\title{
Evaluation of three PCR-based diagnostic assays for detecting mixed Plasmodium infection
}

Tonya Mixson-Hayden ${ }^{1,2}$, Naomi W Lucchi ${ }^{1,2}$, Venkatachalam Udhayakumar ${ }^{1,2^{*}+}$

\begin{abstract}
Background: One of the most commonly used molecular test for malaria diagnosis is the polymerase chain reaction (PCR)-based amplification of the $18 \mathrm{~S}$ ribosomal DNA (rDNA) gene. Published diagnostic assays based on the 185 gene include the "gold standard" nested assay, semi-nested multiplex assay, and one tube multiplex assay. To our knowledge, no one has reported whether the two multiplex methods are better at detecting mixed Plasmodium infections compared to the nested assay using known quantities of DNA in experimentally mixed cocktails.

Findings: Here we evaluated three PCR assays (nested, semi-nested multiplex, and one-tube multiplex) for the simultaneous detection of human malaria parasites using experimentally mixed cocktails of known quantities of laboratory derived DNA. All three assays detected individual species with high sensitivity and specificity when DNA was from any one single species; however, experimentally mixed DNA cocktails with all four species present were correctly identified most consistently with the nested method. The other two methods failed to consistently identify all four species correctly, especially at lower concentrations of DNA -subclinical levels of malaria (DNA equivalent to or less than 10 parasites per microliter).

Conclusions: The nested PCR method remains the method of choice for the detection of mixed malaria infections and especially of sub-clinical infections. Further optimization and/or new molecular gene targets may improve the success rate of detecting multiple parasite species simultaneously using traditional PCR assays.
\end{abstract}

\section{Findings}

Approximately 2 billion people are exposed to malaria with an estimated 250 million clinical cases and about 800,000 deaths annually [1,2]. Four Plasmodium species are known to cause malaria in humans: $P$. falciparum, $P$. vivax, $P$. malariae and $P$. ovale. Many malaria endemic regions report mixed infections of these species and the prevalence of mixed infections varies depending on the geographic region. For example, within India, Hamer et al. [3] reported $9.3 \%$ of malaria cases as mixed P. falciparum/P. vivax infection and Rasheed et al. [4] reported $18 \%$ of cases were $P$. falciparum/P. vivax mixed infection. The clinical presentation of malaria is often nonspecific; consequently many febrile illnesses with unknown etiology are attributed to malaria

\footnotetext{
* Correspondence: vxu0@cdc.gov

+ Contributed equally

'Malaria Branch, Division of Parasitic Diseases, National Center for Zoonotic Vector-Borne and Enteric Diseases, Coordinating Center for Infectious Diseases, Centers for Disease Control and Prevention, Atlanta, GA, USA
}

(resulting in presumptive diagnosis and treatment). Therefore, appropriate laboratory tools are critical for the prompt diagnosis and treatment of malaria. This is especially true for mixed infections which are often not recognized, and as a result, have been underestimated (reviewed in [5] and [6]).

Existing tools for the diagnosis of malaria include microscopy, rapid diagnosis tests (RDTs) and molecular tools (reviewed in [7]). For over a century, microscopy has remained the standard for malaria detection and species determination in many endemic areas. It is relatively inexpensive and allows for the quantification of parasitemia. However, several challenges exist in performing microscopic diagnosis for routine clinical use, especially in malaria endemic countries, including limited availability of well trained microscopists, lack of infrastructure (such as power supply) and training, and the possibility of misdiagnosis due to low parasitemia or mixed infections, even with experienced microscopists $[8,9]$. Furthermore, microscopy may not consistently detect all
C Biomed Central

C 2010 Udhayakumar et al; licensee BioMed Central Ltd. This is an Open Access article distributed under the terms of the Creative Commons Attribution License (http://creativecommons.org/licenses/by/2.0), which permits unrestricted use, distribution, and reproduction in any medium, provided the original work is properly cited. 
infecting species accurately [10]. For example, Plasmodium knowlesi (a monkey malaria recently discovered to also infect humans) has been falsely diagnosed as Plasmodium malariae using routine microscopy, and only through the use of a molecular method was this species correctly identified in humans [11].

RDTs are immunochromatographic tests designed to detect parasite products in human blood. Currently, the two most common RDTs use histidine rich protein-2 (HRP-2) or lactose dehydrogenase (LDH) as target proteins for detection [12]. RDTs are increasingly being used for malaria diagnosis because they are rapid and easier to use especially in resource limited settings. Good quality RDTs are generally as sensitive as microscopy in detecting $P$. falciparum (about 100 parasites per microliter) but they are much less sensitive in identifying other species of malaria parasites. Because RDTs are only qualitative tests, the density of parasitemia cannot be accurately determined. Additionally, RDTs can result in false positives since antigen persists up to one month after the clearance of parasites.

Molecular methods are proving to be useful in species identification and accurate detection of mixed species infections in addition to the detection of subclinical infections [13]. As we move towards malaria elimination/eradication phases, tools to detect sub-clinical levels of infections will aid in malaria control programs. However, the use of molecular tools is hampered by some factors, including high cost of initial equipment setup and the inability to obtain reagents due to infrastructure in many field settings. Additionally traditional molecular methods can be labor intensive and may be prone to amplicon contamination thus requiring advanced technical knowledge. The most commonly used molecular test for malaria diagnosis is the polymerase chain reaction (PCR) -based amplification of the 18S ribosomal DNA (rDNA) gene which allows detection of the different species of human malaria parasites based on different sized PCR products [14-21]. The nested PCR method developed by Snounou et al [20] has been widely used in laboratory studies and in clinical diagnosis, including in a reference diagnostic laboratory in the United States $[13,15,17,22]$. However, this method is time consuming, expensive, and labor intensive as it requires five separate PCR reactions to detect $P$. falciparum, $P$. vivax, $P$. ovale, and $P$. malariae. Sequence variation in strains of $P$. ovale have recently been shown to affect the ability of the nested Snounou primers to identify variants of $P$. ovale, leading to the development of new primers for this species in the nested PCR assay [23]. Alternative multiplex approaches have been developed including a semi-nested multiplex [18] and single round multiplex PCR [16] in an effort to simplify this method, both of which target a region of the $18 \mathrm{~S}$ gene thus far not shown to vary within individual species specific strains of Plasmodium [23]. The semi-nested multiplex PCR [18] utilizes a universal 18S rDNA reverse primer and two forward $18 \mathrm{~S}$ rDNA primers, one specific to the Plasmodium genus and one specific to all mammalian $18 \mathrm{~S}$ rDNA. The primary Plasmodium genus specific forward primer and four species specific reverse primers are used in the secondary reaction. The authors claim that the sensitivity of the semi-nested multiplex is equivalent to detecting 0.1 parasites $/ \mu \mathrm{l}(\mathrm{p} / \mu \mathrm{l})$ in an experimentally mixed $P$. falciparum/P. malariae DNA cocktail, and indicate that the method confirmed microscopically identified coinfections in field samples. The single round multiplex [16] utilizes a Plasmodium genus specific reverse primer with four forward species specific primers. Padley et al. [16] claim the sensitivity of the assay to be 0.02 and $0.004 \mathrm{p} / \mu \mathrm{l}$ for $P$. falciparum and $P$. ovale, respectively, and did not test sensitivity of the assay for $P$. vivax and $P$. malariae. Additionally they claim the assay was able to detect all four species in simulated mixed coinfections; however the data is only shown for $P$. vivax/P. falciparum coinfections. In addition to traditional PCR-based molecular tools, real-time PCR has recently been shown to be a robust alternative for malaria diagnosis. However, several factors inhibit the use of this method in malaria endemic regions including cost, lack of infrastructure, and lack of technical support due to infrastructure problems. Additionally, false negatives for Plasmodium species remain a problem with the current real time assays due to sequence variation and competitive inhibition [24].

The role of molecular tools for the detection of malaria parasites, and especially the detection of mixed infections, is becoming clear [25] and reviewed in [5]. The three previously described PCR-based methods (nested, semi-nested, and single-tube multiplex) are all good alternatives to microscopy and RDTs. However, to our knowledge, no one has evaluated which of these traditional PCR methods is truly better at detecting mixed Plasmodium infections; therefore, we compared the two multiplex methods to the nested method using known quantities of laboratory derived Plasmodium DNA alone and in experimentally mixed cocktails containing all four species of DNA.

\section{Methods}

\section{Parasite culture and DNA extraction}

DNA was extracted from laboratory cultured P. falciparum (3D7) and from monkey derived P. vivax (SV4), $P$. malariae (Uganda I), and $P$. ovale (Nigeria I) using a QIAamp DNA Mini Kit (QIAGEN, Valencia, CA), according to the recommendations by the manufacturer. Thin smears were prepared, stained, and counted for each of the species to determine the percentage 
parasitemia. The total number of red blood cells (RBCs) per microliter was then determined for each species using a coulter counter and the number of malaria infected RBCs per microliter $(\mathrm{p} / \mathrm{uL})$ was calculated using the formula below:

Parasite $/ \mu \mathrm{L}=$ total number of $\mathrm{RBC} / \mu \mathrm{L} \times$ Percentage parasitemia

DNA was isolated from a total of $8 \times 10^{6}$ parasites for each species and suspended in $200 \mu \mathrm{l}$ of sterile TE; therefore, $1 \mu \mathrm{l}$ of sample contained the DNA equivalent of 40,000 parasites. The stock DNA was aliquoted and stored at $-20^{\circ} \mathrm{C}$, from which seven 10 -fold serial dilutions were prepared up to a final concentration equivalent of 0.04 parasite genomes/ $\mu \mathrm{l}$. Assay limits of detection of individual Plasmodium species and detection of multiple species from mixed DNA cocktails were evaluated over seven replicates. Experimentally mixed cocktails were made using two $\mu$ l each of parasite DNA of varying initial concentrations (Table 1). One microliter of the mixture was then used in a $20 \mu \mathrm{l} \mathrm{PCR} \mathrm{reac-}$ tion, equivalent to the final parasitemias of each species given in Additional file 1. Because the field of mixed infections is one that has received little attention (mainly due to diagnosis issues), the DNA ratios for the mixed cocktails were chosen to both, represent low levels of infection, which are commonly missed by microscopy $[5,6,25,26]$, and to simulate varying combinations of mixed infections. In general, equimolar

Table 1 Preparation of mock mixed infections

\begin{tabular}{|c|c|c|c|c|}
\hline Well \# & P. falciparum & P. malariae & P. ovale & P. vivax \\
\hline & \multicolumn{4}{|c|}{ Concentration in Parasites/ $\mu \mathrm{L}$} \\
\hline 1 & 400 & 40 & 400 & 40 \\
\hline 2 & 40 & 40 & 400 & 40 \\
\hline 3 & 40 & 40 & 40 & 40 \\
\hline 4 & 40 & 40 & 4 & 40 \\
\hline 5 & 4 & 40 & 4 & 40 \\
\hline 6 & 4 & 40 & 4 & 4 \\
\hline 7 & 40 & 400 & 40 & 40 \\
\hline 8 & 4 & 400 & 4 & 40 \\
\hline 9 & 400 & 40 & 400 & 400 \\
\hline 10 & 40 & 40 & 4 & 400 \\
\hline 11 & 40 & 4 & 4 & 40 \\
\hline 12 & 400 & 40 & 40 & 400 \\
\hline $13(F)$ & 400 & - & - & - \\
\hline $14(\mathrm{M})$ & - & 400 & - & - \\
\hline $15(0)$ & - & - & 400 & - \\
\hline $16(\mathrm{~V})$ & - & - & - & 400 \\
\hline $17(\mathrm{~N})$ & - & - & - & - \\
\hline
\end{tabular}

Mock mixed infections were prepared as shown. 2 ul of each species was mixed with equal volumes of the other species as shown. One microliter of each mixture was then used for the PCR assay. amounts of each species rarely occur in the field, and it is common for one species in the mixed infections to predominate (reviewed in [25]).

All PCR assays were completed on a BioRad iCycler (BioRad, Hercules, CA). Nested PCR was performed with primers and cycling conditions described by Snounou et al. [20] with modifications described in [27] in a $20 \mu \mathrm{l}$ reaction containing $1 \times$ buffer, $2.5 \mathrm{mM} \mathrm{MgCl} 2,200 \mu \mathrm{M}$ dNTPs, $200 \mathrm{nM}$ primers, and 1.25 units of Taq Polymerase (New England Biolabs, Ipswich, MA). The multiplex semi-nested and multiplex single round PCRs were performed in $20 \mu \mathrm{l}$ reaction using Promega Taq PCR Master Mix (Promega, Madison, WI), per manufacturer's instructions. Multiplex semi-nested PCR was performed with primers described by Rubio et al. [18], modifying the annealing temperatures to $55^{\circ} \mathrm{C}$ for the primary reaction and $58^{\circ} \mathrm{C}$ for the nested reaction. The multiplex single round PCR was performed using primers and cycling conditions described by Padley et al. [16] with the addition of an extension step for one minute at $72^{\circ} \mathrm{C}$. No template control (water) was run in each experiment. Five microliters $(5 \mu \mathrm{l})$ of PCR product were visualized in $2 \%$ agarose gel stained with ethidium bromide.

\section{Results and Discussion}

The nested PCR assay was able to detect single Plasmodium species infections down to $0.4 \mathrm{p} / \mu \mathrm{l}$ (Figure 1A-D). The semi-nested multiplex assay was as sensitive as the nested assay at detecting $P$. falciparum and $P$. vivax, more sensitive at detecting $P$. malariae $(0.04 \mathrm{p} / \mu \mathrm{L})$, and was only able to detect down to $4 \mathrm{p} / \mu \mathrm{L}$ for $P$. ovale (Figure 1I-L). The limit of detection for the multiplex single round protocol was comparable to the other protocols for $P$. falciparum, but was only able to detect down to $4 \mathrm{p} / \mu \mathrm{l}$ for $P$. ovale and $40 \mathrm{p} / \mu \mathrm{l}$ for $P$. malariae and $P$. vivax, a 100-fold difference in sensitivity (Figure 1E-H). Our levels of detection for P. falciparum in a singly infected sample are comparable to those reported by Rubio et al. [18] $(0.1 \mathrm{p} / \mu \mathrm{l})$, while sensitivity was greater than reported by Rubio et al. [18] for P. malariae $(0.1 \mathrm{p} / \mu \mathrm{l})$, and much less sensitive than reported by Padley [16] for $P$. falciparum $(0.02 \mathrm{p} / \mu \mathrm{l})$ and $P$. ovale $(0.004 \mathrm{p} / \mu \mathrm{l})$. Because we had to rely on parasite counts to determine our initial concentrations for the species for which we are unable to culture (i.e. $P$. vivax, $P$. ovale, and $P$. malariae), equal $\mathrm{p} / \mu$ l may not contain equal amounts of DNA due to the presence of schizonts, thus affecting our ability to replicate the sensitivity results previously reported by these authors.

The accuracy of each method to detect all four human Plasmodium species in experimentally mixed infections was assessed over seven replicates. Only the nested PCR assay consistently detected all four species in the cocktails at the sensitivity levels reported for singly infected 


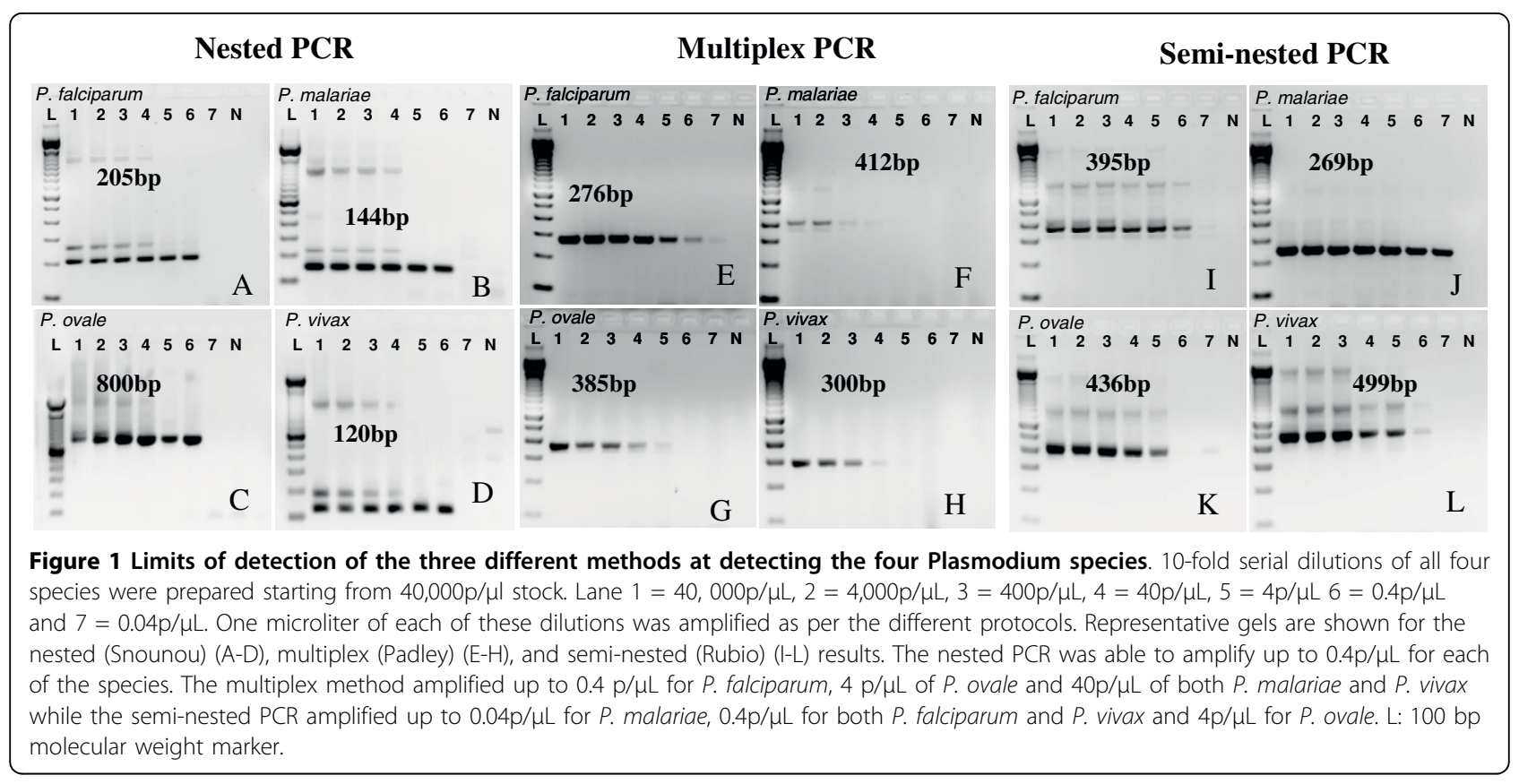

samples (Figure 2A, Additional file 1). However, the assay is more labor intensive than the other two methods, requiring five sets of PCR reactions for systematic detection of all four parasites.

The semi-nested multiplex method detected at best, three of the four species simultaneously ( $P$. falciparum and $P$. vivax and either $P$. malariae or P. ovale, depending on concentration) as shown in Figure $2 \mathrm{C}\left(^{*}\right)$ to as low as $10 \mathrm{p} / \mu \mathrm{l}$. The assay was able to detect parasite concentrations as low as one $\mathrm{p} / \mu \mathrm{l}$ in certain mixing schemes, in agreement with our level of sensitivity found for this assay for singly infected samples. In the mixed DNA cocktails, the semi-nested PCR assay was less sensitive in amplifying $P$. falciparum and $P$. vivax consistently (Figure 2 and Additional file 1). This method was successful in amplifying $P$. falciparum DNA $4 / 7$ times in any of the cocktail combinations tested. The assay performed slightly better with $P$. vivax, correctly identifying the species $6 / 7$ times when parasitemia was $100 \mathrm{p} / \mu \mathrm{l}$. At lower parasitemias, the ability of the semi-nested assay seemed to depend on the proportion of $P$. vivax to $P$. ovale. For instance, when $P$. vivax and $P$. ovale were present in the mixture at $10 \mathrm{p} / \mu \mathrm{l}$ each, the assay correctly identified $P$. vivax $4 / 7$ times (Additional file 1 ), but $5 / 7$ or $6 / 7$ times if $P$. ovale was present at one $\mathrm{p} / \mu \mathrm{l}$. It appears that the performance of this method in amplifying $P$. vivax DNA was negatively affected whenever the concentration of $P$. ovale was higher than $P$. vivax (as noted in the failure of this assay to detect $P$. vivax when the ratio of $P$. ovale DNA to $P$. vivax DNA was 100:10 p/ $\mu \mathrm{l}$, Additional file 1). The assay performed quite well in amplifying $P$. malariae and $P$. ovale in mixed DNA cocktails, generally detecting these species greater than $50 \%$ of the time (Table 1). Occasionally, we were able to amplify all the four species but this was not consistent (2/7 times this method amplified all four species for the mixed DNA cocktail containing $10,10,1,10 \mathrm{p} / \mu \mathrm{l}$ and $1 / 7$ times in the cocktail containing $100,10,10,100 \mathrm{p} / \mu \mathrm{l}$ of $P$. falciparum, $P$. malariae, $P$. ovale, and $P$. vivax). We had better success at amplifying three species simultaneously as shown in Figure $2 \mathrm{C}\left({ }^{*}\right)$. Because the assay performs well for samples infected with only one species of Plasmodium, it is likely that competition for primers contributed to the inability to amplify all four species of Plasmodium simultaneously; therefore, in instances where multiple species of Plasmodium are suspected, the method can be run with only individual species specific primers to increase the specificity of the assay.

The one tube multiplex was the least sensitive, detecting at most only two species simultaneously in the mock mixed infections (Figure $2 \mathrm{~B}$ ). The assay correctly identified $P$. falciparum most consistently in the mixed DNA cocktails; however, it was especially poor at detecting $P$. malariae and $P$. vivax, correctly identifying these species less than $50 \%$ of the time (Additional file $1)$. This method performed reasonably well in identifying $P$. ovale, especially when the concentration of this DNA was equal to or greater than $10 \mathrm{p} / \mu \mathrm{l}$, in agreement with the level of sensitivity found in the singly infected samples. We were able to detect $1 \mathrm{p} / \mathrm{uL}$ of $P$. ovale in the mixed mock infections using the semi-nested assay $22 / 42$ times and the single tube multiplex 7/42 times, which is within an order of magnitude of the level of detection we found for single infections $(4 \mathrm{p} / \mathrm{uL})$. 


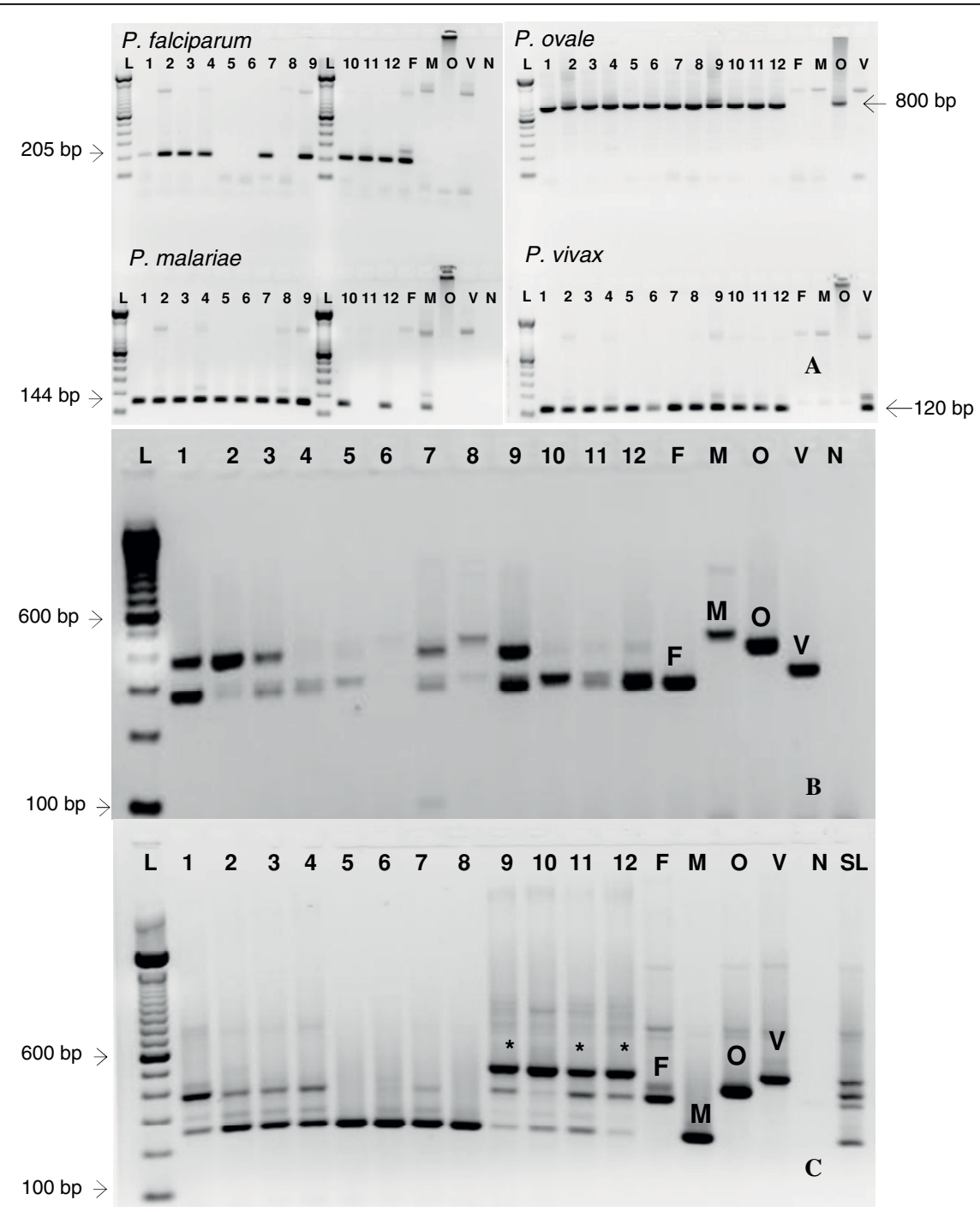

Figure 2 Detection of mock mixed infections using the three different methods. Mock mixed infections were prepared as per Table 1. One microliter of each of the mock mixed infection was amplified according to the different protocols resulting in the final parasite concentrations given by Additional file 1. Representative gels are shown for the nested (Snounou) (A), multiplex (Padley) (B), and semi-nested (Rubio) (C). Lane numbers correspond to the lanes as shown in Additional file 1. F: P. falciparum, M: P. malariae, O: P. ovale, V: P. vivax, L: 100 bp molecular weight marker, SL: Species Ladder created by mixing equal amounts of individually amplified species DNA using Rubio primers.

Occasionally, we were able to detect a lower than expected concentration of parasites in the mock mixed infections for multiplex single tube assays for $P$. vivax (less than $40 \mathrm{p} / \mathrm{uL}, 9 / 54$ times), which was most probably by chance only. Competition between the primer pairs likely contributed to the inconsistencies of the semi-nested multiplex and single tube multiplex methods to correctly identify multiply infected samples.

Cost of each assay was calculated and included the price of reagents and plastic consumables (tips, tubes, etc.) for a single sample. The nested method was the most expensive (8 USD/sample), followed by the semi-nested method (5 USD/sample), and single tube multiplex (4 USD/sample).
Clearly the nested PCR method is the best PCR-based assay for the diagnosis of mixed infections and of subclinical infections among the three methods tested in this study. However, researchers should be aware of the sequence variability within strains of $P$. ovale, and thus utilize the primers for this species as described in [23]. Many of the inhabitants of high malaria endemic regions may harbor high levels of malaria parasites with no clinical symptoms (subclinical/asymptomatic infections) mainly due to acquired partial immunity. These infections are commonly missed by microscopy and RDT which usually detect $50-100 \mathrm{p} / \mathrm{uL}$ at best. As we move towards the malaria elimination/eradication phases 
suggested by the malaria community, subclinical infections will be common due to an increase in intervention programs; therefore, tools to detect sub-clinical levels of infections will be critical to determine the success of malaria control programs. Only molecular tools have been shown to accurately detect subclinical levels of infections. In this study, the nested PCR method, though tedious in nature, was the only method that consistently and accurately detected these levels. In addition, mixed infections have often been unrecognized or underreported $[5,6,25,26]$ mainly due to limited detection tools [25]. Indeed, the use of molecular tools for malaria diagnosis has revealed that low-level mixed infections are common [26]. Further optimization of primers and reaction conditions could possibly improve the semi-nested and multiplex methods. This study suggests that diagnostic assays need to be given careful consideration before use in clinical diagnostic settings due to the probability of a high number of false negatives if these two multiplex methods are used. In areas where there are few species circulating, the semi-nested assay may be an acceptable assay; however, in areas where many species are circulating, the nested PCR assay would be the most appropriate diagnostic assay of these three. Alternative molecular methods using real time PCR $[28,29]$ and loop mediated isothermal amplification (LAMP) [30-32] assays have been reported and further evaluation of these newer methods will be necessary to determine their utility for malaria diagnosis in the field. It is important to note that in at least one real time PCR $18 \mathrm{~S}$ assay, it has been shown that if there is a greater than 10 fold difference in the parasitemia in a mixed infection, the species with the greater concentration of DNA will be the only species detected [24]. In addition, no reports have been made, to date, of multiplex-LAMP assays. Further research to develop simpler and field-usable molecular tools will enhance prompt and accurate diagnosis of malaria in endemic regions. The release of the whole genomes of $P$. falciparum and $P$. vivax should enable the identification of potential unique species-specific molecular targets to overcome some of the limitations associated with the existing multiplex molecular tools.

Additional file 1: The success rate of each assay in detecting $P$. falciparum, $P$. malariae, $P$. ovale, and $P$. vivax at the varying parasite concentration within mock-mixed infections. The nested and multiplex semi-nested PCR assay was replicated seven times for each of the mock-mixed infections, while only six replications were considered for the multiplex single round due to lack of amplification of the positive controls in one replication.

\section{Acknowledgements}

TMH and NWL were supported by the American Society of Microbiology/ CDC Postdoctoral Fellowship. The financial support from CDC/EID Funding is greatly appreciated. We thank Dr. John Barnwell and Ms. Kathy Grady for providing the Plasmodium DNA. We thank Dr. Alexandre DaSilva for support and critical review.

\section{Author details}

${ }^{1}$ Malaria Branch, Division of Parasitic Diseases, National Center for Zoonotic Vector-Borne and Enteric Diseases, Coordinating Center for Infectious Diseases, Centers for Disease Control and Prevention, Atlanta, GA, USA. ${ }^{2}$ Atlanta Research and Education Foundation, Decatur GA, USA.

\section{Authors' contributions}

$\mathrm{TMH}$ and NWL carried out the molecular assays and drafted the manuscript. VU conceived of and designed the study and helped draft the manuscript. All authors have read and approved the final manuscript.

\section{Competing interests}

The authors declare that they have no competing interests.

Received: 8 October 2009 Accepted: 31 March 2010

Published: 31 March 2010

\section{References}

1. Snow RW, Guerra CA, Noor AM, Myint HY, Hay SI: The global distribution of clinical episodes of Plasmodium falciparum malaria. Nature 2005, 415:214-217

2. WHO: The world malaria report. 2008.

3. Hamer DH, Singh MP, Wylie BJ, Yeboah-Antwi K, Tuchman J, Desai M, Udhayakumar V, Gupta P, Brooks MI, Shukla MM, et al: Burden of malaria in pregnancy in Jharkhand State, India. Malaria Journal 2009, 8:210.

4. Rasheed A, Saeed S, Khan SA: Clinical and laboratory findings in acute malaria caused by various plasmodium species. Journal of the Pakistani Medical Association 2009, 59:220-223.

5. Mayxay M, Pukrittayakamee S, Newton PN, White NJ: Mixed-species malaria infections in humans. Trends in Parasitology 2004, 20:233-240.

6. Zimmerman PA, Mehlotra RK, Kasehagen LJ, Kazura JW: Why do we need to know more about mixed Plasmodium species infections in humans? Trends in Parasitology 2004, 20:440-447.

7. Bronzan RN, McMorrow ML, Kachur SP: Diagnosis of malaria: challenges for clinicians in endemic and non-endemic regions. Molecular Diagnosis and Therapy 2008, 12:299-306.

8. Hanscheid T: Current strategies to avoid misdiagnosis of malaria. Clinical Microbiology and Infection 2003, 9:497-504.

9. Payne D: Use and limitations of light microscopy for diagnosing malaria at the primary health care level. Bulletin of the World Health Organization 1988, 66:621-626.

10. Milne LM, Kyi MS, Chiodini PL, Warhurst DC: Accuracy of routine laboratory diagnosis of malaria in the United Kingdom. Journal of Clinical Pathology 1994, 47:740-742.

11. Singh B, Kim Sung L, Matusop A, Radhakrishnan A, Shamsull SS, CoxSingh J, Thomas A, Conway DJ: A large focus of naturally acquired Plasmodium knowlesi infections in human beings. Lancet 2004, 363:1017-1024.

12. Bell $D$, Wongsrichanalai $C$, Barnwell JW: Ensuring quality and access for malaria diagnosis: how can it be achieved? Nature Reviews Microbiology 2006, 4:682-695

13. Mens P, Spieker N, Omar S, Heijnen M, Schallig H, Kager PA: Is molecular biology the best alternative for diagnosis of malaria to microscopy? A comparison between microscopy, anitgen detection and molecular tests in rural Kenya and urban Tanzania. Tropical Medicine and International Health 2007, 12:238-244.

14. Ciceron L, Jaureguiberry G, Gay F, Danis M: Development of a Plasmodium PCR for monitoring efficacy of antimalarial treatment. Journal of Clinical Microbiology 1999, 37:35-38.

15. Gal S, Fidler C, Truner S, Lo YM, Roberts DJ, Wainscoat JS: Detection of Plasmodium falciparum DNA in plasma. Annals of the New York Academy of Sciences 2001, 945:234-238.

16. Padley D, Moody AH, Chiodini PL, Saldanha J: Use of a rapid, singleround, mutiplex PCR to detect malarial parasites and identify the species present. Annals of Tropical Medicine and Parasitology 2003, 97:131-137. 
17. Roper C, Elhassan IM, Hviid L, Giha H, Richardson W, Babiker H, Satti GMH, Theander TG, Arnot DE: Detection of very low levels of Plasmodium falciparum infections using the nested polymerase chain reaction and a reassessment of the epidemiology of unstable malaria in Sudan. American Journal of Tropical Medicine and Hygiene 1996, 54:325-331.

18. Rubio JM, Benito A, Berzosa PJ, Roche J, Puente S, Subirats M, LopezVelez R, Garcia L, Alavar J: Usefulness of seminested multiplex PCR in surveillance of imported malaria in Spain. Journal of Clinical Microbiology 1999, 37:3260-3264.

19. Singh N, Valecha N, Sharma VP: Malaria diagnosis by field workers using an immunochromatographic test. Transactions of the Royal Society of Tropical Medicine and Hygiene 1997, 91:396-397.

20. Snounou GS, Viriyakosol S, Zhu XP, Jarra W, Pinheiro L, do Rosario VE, Thaithong S, Brown KN: High sensitivity of detection of human malaria parasites by the use of nested polymerase chain reaction. Molecular and Biochemical Parasitology 1993, 61:315-320.

21. Kain KC, Harrington MA, Tennyson S, Keystone JS: Imported malaria: prospective analysis of problems in diagnosis and management. Clinical Infectious Diseases 1998, 27:142-149.

22. Johnson SP, Pieniazek NJ, Xayavong MV, Slemenda SB, Wilkins PP, da Silva AJ: PCR as a confirmatory technique for laboratory diagnosis of malaria. Journal of Clinical Microbiology 2006, 44:1087-1089.

23. Calderaro A, Piccolo G, Perandin F, Gorrini C, Peruzzi S, Zuelli C, Ricci L, Manca N, Dettori G, Chezzi C, Snounou G: Genetic polymorphisms influence Plasmodium ovale PCR detection accuracy. Journal of Clinical Microbiology 2007, 45:1624-1627.

24. Bialasiewicz S, Whiley DM, Nissen MD, Sloots TP: Impact of competitive inhibition and sequence variation upon the sensitivity of malaria PCR. Journal of Clinical Microbiology 2007, 45.

25. Mueller I, Widmer S, Michel D, Maraga S, McNamara DT, Kiniboro B, Sie A, Smith TA, Zimmerman PA: High sensitivity dection of Plasmodium species reveals positive correlations between infections of different species, shifts in age distribution and reduced local variation in Papua New Guinea. Malaria Journal 2009, 8:41.

26. Mueller I, Zimmerman PA, Reeder JC: Plasmodium malariae and Plasmodium ovale-the "bashful" malaria parasites. Trends in Parasitology 2007, 23:278-283.

27. Singh B, Bobogare A, Cox-Singh J, Snounou G, Abdullah MS, Rahman HA: A genus- and species-specific nested polymerase chain reaction malaria detection assay for epidemiologic studies. American Journal of Tropical Medicine and Hygiene 1999, 60:687-692.

28. de Monbrison F, Angei C, Staal A, Kaiser K, Picot S: Simulateous identification of the four human Plasmodium species and quantification of Plasmodium DNA load in human blood by real-time polymerase chain reaction. Transactions of the Royal Society of Tropical Medicine and Hygiene 2003, 97:387-390.

29. Rougemont M, Van Saanen M, Sahli R, Hinrikson HP, Bille J, Jaton K: Detection of four Plasmodium species in blood from humans by $18 \mathrm{~S}$ rRNA gene subunit-based and species-specific real-time PCR asays. Journal of Clinical Microbiology 2004, 2004:5636-5643.

30. Han ET, Watanabe R, Sattabongkot J, Khuntirat B, Sirichaisinthop J, Iriko H, Jin L, Takeo S, Tsuboi T: Detection of four Plasmodium species by genus and species-specific loop-mediated isothermal amplification for clinical diagnosis. Journal of Clinical Microbiology 2007, 45:2521-2528.

31. Poon LL, Wong BW, Ma EH, Chan KH, Chow LM, Abeyewickreme W, Tangpukdee N, Yuen KY, Guan Y, Looareesuwan S, Pieris JS: Sensitive and inexpensive molecular test for falciparum malaria: detecting Plasmodium falciparum DNA directly from heat-treated blood by loop-mediated isothermal amplification. Clinical Chemistry 2006, 52:303-306.

32. Aonuma H, Suzuki M, Iseki H, Perera N, Nelson B, Igarashi I, Yagi T, Kanuka H, Fukumoto S: Rapid identification of Plasmodium- carrying mosquitoes using loop-mediated isothermal amplification. Biochemical and Biophysical Research Communications 2008, 376:671-676.

doi:10.1186/1756-0500-3-88

Cite this article as: Mixson-Hayden et al:: Evaluation of three PCR-based diagnostic assays for detecting mixed Plasmodium infection. BMC Research Notes 2010 3:88.

\section{Submit your next manuscript to BioMed Central and take full advantage of:}

- Convenient online submission

- Thorough peer review

- No space constraints or color figure charges

- Immediate publication on acceptance

- Inclusion in PubMed, CAS, Scopus and Google Scholar

- Research which is freely available for redistribution

Submit your manuscript at www.biomedcentral.com/submit
Biomed Central 